\title{
BMJ Open Identification of adults with sepsis in the prehospital environment: a systematic review
}

\author{
Michael A Smyth, ${ }^{1,2,3}$ Samantha J Brace-McDonnell,, ${ }^{1,4}$ Gavin D Perkins ${ }^{1,4}$
}

To cite: Smyth MA, BraceMcDonnell SJ, Perkins GD. Identification of adults with sepsis in the prehospital environment: a systematic review. BMJ Open 2016;6: e011218. doi:10.1136/ bmjopen-2016-011218

- Prepublication history and additional material is available. To view please visit the journal (http://dx.doi.org/ 10.1136/bmjopen-2016011218).

Received 25 January 2016 Revised 17 April 2016 Accepted 26 May 2016

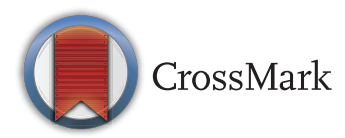

${ }^{1}$ Clinical Trials Unit, University of Warwick, Coventry, UK

${ }^{2}$ Midlands Air Ambulance, Stourbridge, UK

${ }^{3}$ West Midlands Ambulance Service NHS Foundation

Trust, Dudley, UK

${ }^{4}$ Heart of England Hospital NHS Foundation Trust, Birmingham, UK

Correspondence to Michael A Smyth; m.a. smyth@warwick.ac.uk

\section{ABSTRACT}

Objective: Early identification of sepsis could enable prompt delivery of key interventions such as fluid resuscitation and antibiotic administration which, in turn, may lead to improved patient outcomes. Limited data indicate that recognition of sepsis by paramedics is often poor. We systematically reviewed the literature on prehospital sepsis screening tools to determine whether they improved sepsis recognition.

Design: Systematic review. The electronic databases MEDLINE, EMBASE, CINAHL, the Cochrane Library and PubMed were systematically searched up to June 2015. In addition, subject experts were contacted. Setting: Prehospital/emergency medical services (EMS).

Study selection: All studies addressing identification of sepsis (including severe sepsis and septic shock) among adult patients managed by EMS.

Outcome measures: Recognition of sepsis by EMS clinicians.

Results: Owing to considerable variation in the methodological approach adopted and outcome measures reported, a narrative approach to data synthesis was adopted. Three studies addressed development of prehospital sepsis screening tools. Six studies addressed paramedic diagnosis of sepsis with or without use of a prehospital sepsis screening tool.

Conclusions: Recognition of sepsis by ambulance clinicians is poor. The use of screening tools, based on the Surviving Sepsis Campaign diagnostic criteria, improves prehospital sepsis recognition. Screening tools derived from EMS data have been developed, but they have not yet been validated in clinical practice. There is a need to undertake validation studies to determine whether prehospital sepsis screening tools confer any clinical benefit.

\section{INTRODUCTION}

Sepsis is a systemic response to infection, which may progress to severe sepsis and septic shock. ${ }^{1}$ In the UK, there are an estimated 102000 cases of severe sepsis each year resulting in $>37000$ deaths. $^{2}$ It has been reported that more than two-thirds of severe sepsis cases are initially seen in the emergency department $(\mathrm{ED})^{3}$ and around half of ED

\section{Strengths and limitations of this study}

- Despite using very broad search criteria, little robust evidence regarding prehospital sepsis screening was identified.

- The studies found employed disparate methodologies, exhibit significant heterogeneity, generally involve small numbers of patients (limiting the precision of reported results) and were invariably of very low quality.

- The conclusions that can be drawn from this systematic review are, therefore, limited and findings should be interpreted with caution.

sepsis patients arrive by ambulance. ${ }^{4-9}$ Patients with sepsis arriving at the ED via emergency medical services (EMS) are likely to be sicker than those arriving by other means, ${ }^{5-10}$ and up to $80 \%$ of patients with severe sepsis admitted to intensive care from the ED will have been transported by EMS. ${ }^{11}$

Although the burden of sepsis upon ambulance services is not well understood, data from Guerra et $a l^{12}$ suggested that $6.9 \%$ of EMS transports were for patients with infection. It is further estimated that $8-10 \%$ of EMS patients who have infection will be diagnosed with sepsis. ${ }^{12}{ }^{13}$ Following a 10-year observational study, Seymour et $\mathrm{al}^{14}$ reported the incidence of severe sepsis in a North American EMS system to be 3.3 per 100 ambulance transports. Extrapolation of data reported by McClelland and Jones ${ }^{15}$ suggests a lower incidence of sepsis cases in one region of the UK, of $\sim 1.8 \%$ of EMS calls.

In-hospital data indicate that early identification and initiation of treatment of severe sepsis is associated with reduced mortality. ${ }^{2} 16$ It has been argued that there is an opportunity for ambulance clinicians to improve outcomes for this population in the same manner as they do with other time critical, life-threatening conditions such as acute myocardial infarction, ${ }^{17}$ stroke $^{18}$ and major trauma. $^{19}$ Early recognition of sepsis by 
ambulance clinicians could reduce time to delivery of a limited number of interventions prior to arrival at the ED; however, evidence suggests that recognition of sepsis by paramedics is often poor. ${ }^{72}{ }^{20-22}$ Use of a prehospital sepsis screening tool has been advocated, suggesting that it would lead to improved recognition, and potentially earlier initiation of key interventions such as fluid resuscitation and antibiotic administration prior to arriving at hospital. ${ }^{52324}$

\section{OBJECTIVE}

The objective of this study was to determine whether, among adult patients presenting to EMS, the use of a prehospital sepsis screening tool by ambulance clinicians, compared to ambulance clinician judgement alone, improves identification of sepsis.

\section{DESIGN}

We followed the Grading of Recommendations, Assessment, Development and Evaluation (GRADE) Working Group methodology ${ }^{25}$ to conduct the review and Preferred Reporting Items for Systematic Reviews and Meta-Analyses recommendations to report our findings. ${ }^{26}$ The review is registered with the International Prospective Register of Systematic Reviews (CRD42014007654).

\section{SETTING}

Adult patients managed by EMS in the prehospital environment.

\section{STUDY SELECTION}

\section{Electronic searches}

We searched MEDLINE, EMBASE, CINAHL, the Cochrane Library and PubMed. No language restrictions were placed. Conference proceedings/meeting abstracts were included to capture grey literature.

\section{Search terms/search strategy}

Search strategies were developed for each database, starting with MEDLINE (see online supplementary appendix 1 ). The MEDLINE search strategy was adapted for each subsequent database. Initial searches were conducted in July 2014 with a second search completed at the end of June 2015 (including articles published up to 28 June 2015).

\section{Inclusion criteria}

- Language. no restrictions were placed.

- Publication type: original research published in peerreviewed journals and conference proceedings.

- Study design: systematic reviews, meta-analyses, randomised controlled trials, case-control studies, cohort studies and cross-sectional studies.

- Study population: adult patients managed by EMS. Populations could comprise a mix of adult and child participants if results were reported separately.

- Case definition: no restrictions as to severity of sepsis.

\section{Exclusion criteria}

- Publication type: narrative/literature reviews, letters, editorials, commentaries, books and book chapters, lectures and addresses, and consensus statements.

- Study design: case reports and qualitative studies.

- Study population: In-hospital studies. Mixed adult and child population without distinct reporting, child population and animals.

\section{Other}

Reference lists of included manuscripts were scrutinised. Subject experts were contacted to identify studies missed by electronic searches.

\section{Data collection and analysis}

Studies were screened in two stages. In the first stage, two reviewers (MAS and SJB-M) independently reviewed each citation and abstract against the inclusion criteria. Citations rated as 'include' by either reviewer were considered relevant, and citations rated as 'exclude' by both reviewers were rejected. In the second stage, the full manuscripts of included citations were again independently screened by two reviewers (MAS and SJB-M) rating each manuscript as 'include', 'maybe' or 'exclude' against the inclusion criteria. If both reviewers rated a manuscript as 'include', it was automatically included for critical appraisal. If both reviewers rated a manuscript as 'exclude', it was automatically rejected. Where a manuscript was selected as 'include' by a single reviewer, or was selected as 'maybe' by one or both reviewers, the reviewers discussed if the manuscript should be included or excluded. If the reviewers were unable to agree, a third independent reviewer (GDP) was available to adjudicate.

\section{OUTCOME MEASURES}

We included any study that reported prehospital sepsis screening or development of prehospital sepsis screening tools and compared accuracy of prehospital diagnosis with in-hospital diagnosis.

\section{RESULTS}

Database searches yielded 4366 citations. Duplicate citations were removed manually within EndNote (V.X7 Thompson Scientific, Carlsbad, California, USA) by a single reviewer (MAS) providing 2958 unique citations. After the first stage of screening, 78 citations were retained and 2880 citations were rejected. Inter-rater agreement for first-stage screening, calculated using Cohen's $\kappa$ statistic, was 0.87 (95\% CI 0.81 to 0.92). During the second stage of screening, 78 manuscripts were reviewed, 70 were discarded following assessment and 8 were retained for critical appraisal. Inter-rater agreement for second-stage screening, calculated using Cohen's к statistic, was 0.82 (95\% CI 0.68 to 0.97 ).

No additional citations were identified by scrutinising the reference lists of included manuscripts. One additional 
study, ${ }^{15}$ a manuscript pending publication, was identified by contacting subject experts. In total, nine studies are included in the final analysis (see figure 1 and online supplementary material).

\section{Characteristics of included studies}

No randomised controlled trials were identified; all included studies were observational in nature. Three studies were published in abstract form only. ${ }^{20} 27 \quad 28$ Studies originate from five countries, comprising a total of 147320 patients. All studies were published in English. The median year of publication was 2013. The data from included studies were extracted and entered into relevant tables by a single reviewer (MAS) and verified by a second reviewer (SJB-M).

Three studies were concerned with derivation of screening tools. ${ }^{29-31}$ Six studies addressed the identification of sepsis within EMS. ${ }^{12} 1520212728$ Collectively, six prehospital screening tools were identified in the course of the review (critical illness score, ${ }^{32}$ Prehospital Recognition of Severe Sepsis (PRESS) score, ${ }^{31}$
Prehospital Early Sepsis Detection (PRESEP) score, ${ }^{30}$ Robson tool, ${ }^{21}{ }^{30}$ modified Robson tool ${ }^{15}$ and BAS $90-30-90^{21}{ }^{30}$ ); a single study reported the accuracy of the Modified Early Warning Score (MEWS).$^{30}$ None of the studies were prospective and no studies were designed specifically to validate a prehospital sepsis screening tool in clinical practice.

All studies used hospital sepsis diagnosis as the reference standard; however, hospital diagnosis was variably determined by Surviving Sepsis Campaign diagnostic criteria, International Classification of Disease coding, ED diagnosis (without description of how diagnosis was determined) or discharge diagnosis (without description of how diagnosis was determined).

\section{Risk of bias}

Bias within observational studies was assessed across the domains of failure to develop and apply appropriate eligibility criteria (inclusion of control population), flawed measurement of exposure and outcome, failure to adequately control confounding and incomplete

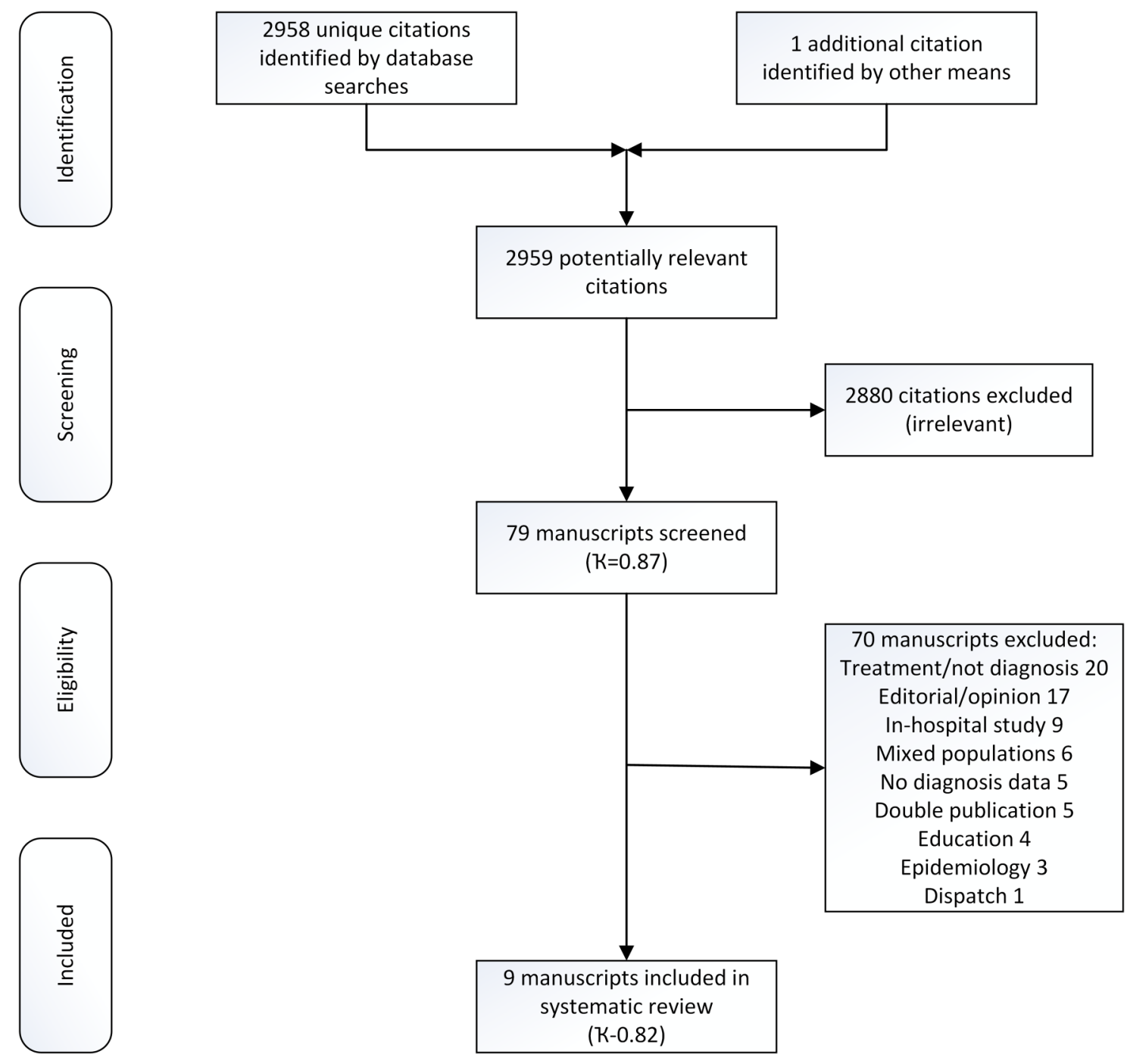

Figure 1 PRISMA flow chart. 
follow-up. Two reviewers (MAS and SJB-M) independently assessed each article across the bias domains with each being rated as high risk, low risk or level of risk unclear as per GRADE recommendations. ${ }^{33}$ Studies with high risk in one or more domains were considered to be at high risk of bias overall. Similarly studies with low risk for all domains were considered to be at low risk of bias overall. Otherwise, studies were considered to have an unclear risk of bias. Risk of bias assessments are reported in table 1 .

\section{Quality of evidence}

Study design informed initial quality assumptions. No randomised controlled trials were identified. Nonrandomised (observational) studies were initially presumed to be 'low quality'. Two reviewers (MAS and SJB-M) appraised each study across the five core GRADE domains of risk of bias, ${ }^{33}$ inconsistency, ${ }^{34}$ indirectness, ${ }^{35}$ imprecision $^{36}$ and other considerations (including publication bias) ${ }^{37}$ (see online supplementary material). Where concerns were identified, it lowered the overall quality assumptions. Similarly, quality could have been adjusted upward if, for example, a large treatment effect or dose-response had been noted, which subsequently raised our confidence in the estimate of effect. ${ }^{38}$ Quality of evidence, across each outcome of interest, is reported as follows (table 2):

- High quality: We are very confident that the true effect lies close to that of the estimate of effect.

- Moderate quality: We are moderately confident in the effect estimate: the true effect is likely to be close to the estimate of effect, but there is a possibility that it is substantially different.

- Low quality: Our confidence in the effect is limited: the true effect may be substantially different from the estimate of the effect.

- Very low quality: We have very little confidence in the effect estimate: the true effect is likely to be substantially different from the estimate of effect.

\section{Data synthesis}

There was considerable variation in the methodological approach adopted across the studies as well as the outcome measures reported. The majority of studies identified involve limited numbers of participants, without control and intervention cohorts. Because of these differences, the studies did not answer a unique research question; thus, meta-analysis was not appropriate. A narrative approach to data synthesis was adopted.

\section{Derivation of prehospital sepsis screening tools}

We identified very low-quality evidence (downgraded for indirectness and imprecision), from three observational studies, ${ }^{30-32}$ addressing derivation of prehospital sepsis screening tools (see table 2). Each of the studies adopted a similar approach to screening tool development. Identification of candidate predictors varied

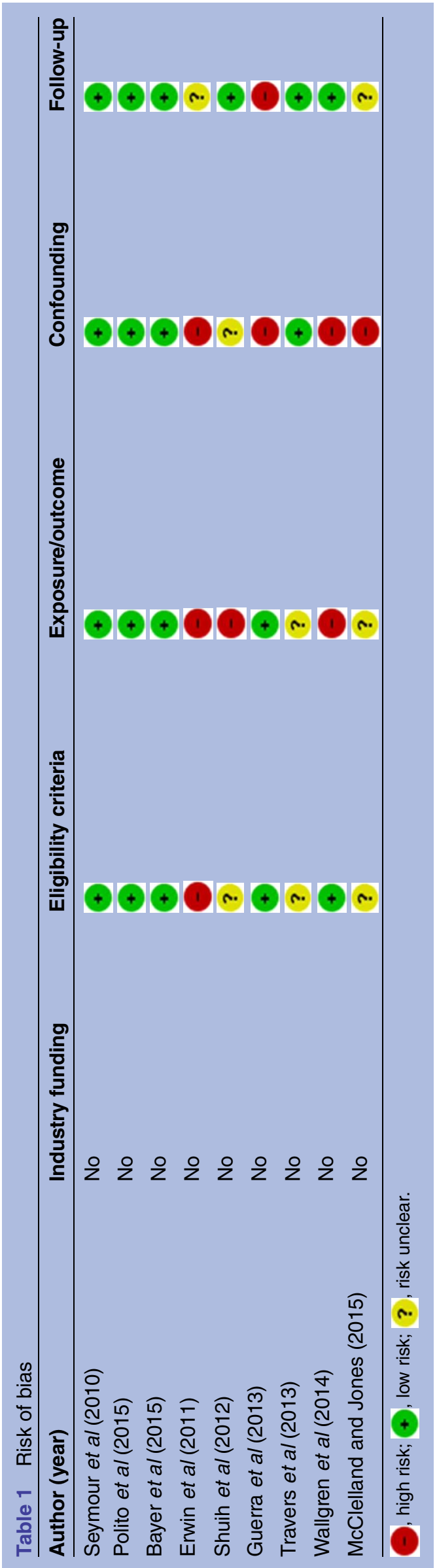




\begin{tabular}{|c|c|c|c|c|c|c|c|c|c|}
\hline $\begin{array}{l}\text { No. of } \\
\text { studies } \\
\end{array}$ & $\begin{array}{l}\text { No. of } \\
\text { patients }\end{array}$ & $\begin{array}{l}\text { Study } \\
\text { design }\end{array}$ & $\begin{array}{l}\text { Risk of } \\
\text { bias }\end{array}$ & Inconsistency & Indirectness & Imprecision & Other & Findings & $\begin{array}{l}\text { Level of } \\
\text { evidence }\end{array}$ \\
\hline \multicolumn{10}{|c|}{ Sepsis recognition by EMS (use of screening tool not reported) } \\
\hline 3 & 963 & Non-RCT & $\begin{array}{l}\text { Very } \\
\text { serious } \neq\end{array}$ & None & Not serious§ & $\begin{array}{l}\text { Very } \\
\text { serious }\end{array}$ & $\begin{array}{l}\text { Very } \\
\text { serioust† }\end{array}$ & 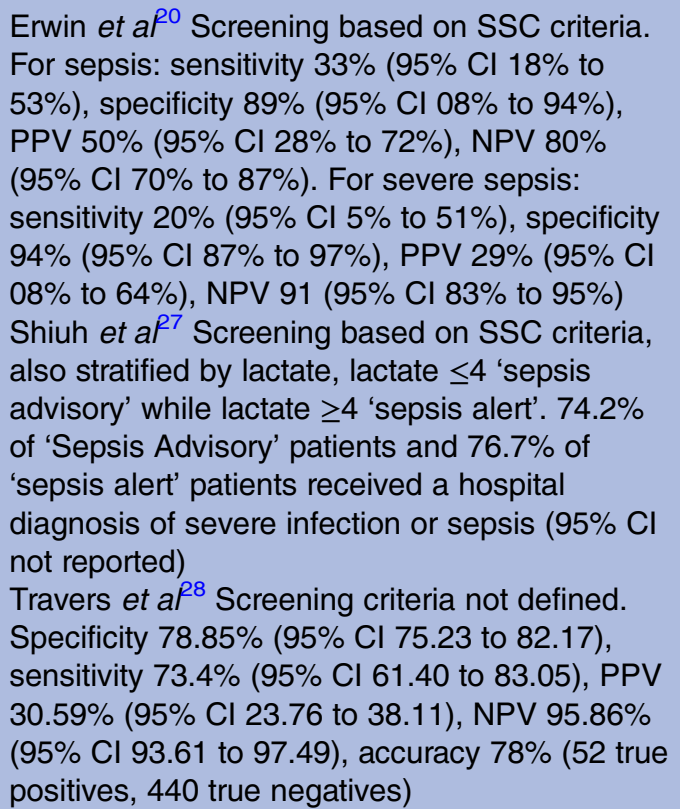 & $\begin{array}{l}\oplus \odot \odot \odot \\
\text { very low }\end{array}$ \\
\hline
\end{tabular}

*Seymour et al CIS not specific to sepsis (CIS intended to identify all cases of critical illness). Polito et al and Bayer et al studies limited to single EMS systems, Bayer et al physician-based EMS.

†Polito et al failed to report Cls, small sample size in Bayer et al study.

$\ddagger$ All studies patient selection/eligibility criteria, exposure/outcome reporting, confounding.

§Guerra et al, Erwin et al and Shiuh et al include lactate measurement (not widely available within EMS). In majority of studies, the population limited to single EMS agency/hospital so limited generalisablity. Bayer et al used physician-based EMS.

TAll included studies have small sample sizes, thus imprecise point estimates. In several studies, Cls are not reported.

${ }^{* *}$ Guerra et al publication bias likely.

††Published in abstract only, unable to reliably critically appraise.

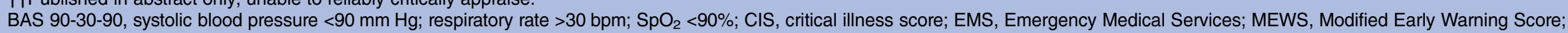
modified Robson, Robson tool with addition of $\mathrm{SpO}_{2}$; non-RCT, non-randomised (observational) study; NPV, negative predictive value; PPV, positive predictive value; PRESEP, Prehospital

Early Sepsis Detection; SSC, Surviving Sepsis Campaign. 
Table 3 Variables used in screening tools

\begin{tabular}{|c|c|c|c|c|c|c|c|c|c|c|c|c|c|}
\hline \multirow[b]{2}{*}{ Author (screening tool) } & \multicolumn{13}{|l|}{ Variable } \\
\hline & $\begin{array}{l}\text { Respiratory } \\
\text { rate }^{\star}\end{array}$ & $\begin{array}{l}\text { Heart } \\
\text { rate }^{\star}\end{array}$ & Temperature $^{*}$ & LOC† & $\mathrm{SpO}_{2} \mathrm{\dagger}$ & $\begin{array}{l}\text { Blood } \\
\text { pressure† }\end{array}$ & Lactate† & $\begin{array}{l}\text { Blood } \\
\text { glucose }\end{array}$ & Skin & CBRT & $\begin{array}{l}\text { Dispatch } \\
\text { category }\end{array}$ & Location & Age \\
\hline Seymour (CIS) & $\bullet$ & • & & & $\cdot$ & $\bullet$ & & & & $\cdot$ & & & \\
\hline Polito (PRESS) & & & - & & - & - & & & & & - & - & - \\
\hline Bayer (PRESEP) & - & - & - & & - & - & & & & & & & \\
\hline Wallgren (Robson tool) & - & - & - & - & & & & - & & & & & \\
\hline Wallgren (BAS 90-30-90) & - & & & & - & - & & & & & & & \\
\hline McClelland (modified & $\bullet$ & • & • & - & • & & & • & & & & & \\
\hline Robson tool) & & & & & & & & & & & & & \\
\hline Bayer (MEWS) & - & - & - & - & & - & & & & & & & \\
\hline Erwin (unnamed) & - & - & - & - & & & - & & & - & & & \\
\hline Guerra (unnamed) & - & - & - & & & - & - & & & & & & \\
\hline Shiuh (unnamed) & - & - & - & & & & - & & & & & & \\
\hline
\end{tabular}

*SIRS criteria.

tOrgan dysfunction.

CBRT, capillary bed refill time; CIS, critical illness score; LOC, reduced level of consciousness; MEWS, Modified Early Warning Score; PRESEP, Prehospital Early Sepsis Detection; SIRS,

systemic inflammatory response syndrome; $\mathrm{SpO}_{2}$, oxygen saturations.

\section{Table 4 Performance of screening tools}

\begin{tabular}{|c|c|c|c|c|}
\hline Author & Sensitivity & Specificity & PPV & NPV \\
\hline Seymour (CIS) & $0.76(95 \% \mathrm{Cl} 0.75$ to 0.77$)$ & Not reported & Not reported & Not reported \\
\hline Polito (PRESS) & 0.85 (95\% Cl not reported) & $0.47(95 \% \mathrm{Cl}$ not reported $)$ & $0.19(95 \% \mathrm{Cl}$ not reported $)$ & $0.96(95 \% \mathrm{Cl}$ not reported) \\
\hline Bayer (PRESEP) & $0.85(95 \% \mathrm{Cl} 0.77$ to 0.92$)$ & $0.86(95 \% \mathrm{Cl} 0.82$ to 0.90$)$ & 0.63 (95\% Cl not reported) & $0.95(95 \% \mathrm{Cl}$ not reported) \\
\hline McClelland (sepsis) (modified Robson tool) & $0.43(95 \% \mathrm{Cl} 0.28$ to 0.58$)$ & $0.14(95 \% \mathrm{Cl} 0$ to 0.40$)$ & Not reported & Not reported \\
\hline McClelland (severe sepsis) (modified Robson tool) & $0.30(95 \% \mathrm{Cl} 0.12$ to 0.47$)$ & $0.77(95 \% \mathrm{Cl} 0.60$ to 0.95$)$ & Not reported & Not reported \\
\hline Bayer (modified Robson tool) & $0.95(95 \% \mathrm{Cl}$ not reported $)$ & $0.43(95 \% \mathrm{Cl}$ not reported) & $0.32(95 \% \mathrm{Cl}$ not reported $)$ & $0.97(95 \% \mathrm{CI}$ not reported) \\
\hline Wallgren (sepsis) (Robson tool) & $0.75(95 \% \mathrm{Cl}$ not reported $)$ & Not reported & Not reported & Not reported \\
\hline Wallgren (severe sepsis) (Robson tool) & 0.93 (95\% Cl not reported) & Not reported & Not reported & Not reported \\
\hline Bayer (BAS 90-30-90) & $0.62(95 \% \mathrm{Cl}$ not reported) & $0.83(95 \% \mathrm{Cl}$ not reported $)$ & $0.51(95 \% \mathrm{Cl}$ not reported $)$ & $0.89(95 \% \mathrm{Cl}$ not reported) \\
\hline Wallgren (sepsis) (BAS 90-30-90) & $0.73(95 \% \mathrm{Cl}$ not reported) & Not reported & Not reported & Not reported \\
\hline Wallgren (severe sepsis) (BAS 90-30-90) & 0.70 (95\% Cl not reported) & Not reported & Not reported & Not reported \\
\hline Bayer (MEWS) & $0.74(95 \% \mathrm{Cl}$ not reported $)$ & $0.75(95 \% \mathrm{Cl}$ not reported) & $0.45(95 \% \mathrm{Cl}$ not reported $)$ & $0.91(95 \% \mathrm{Cl}$ not reported) \\
\hline Guerra & 0.48 (95\% Cl not reported) & Not reported & Not reported & Not reported \\
\hline Erwin (sepsis) & 0.33 (95\% $\mathrm{Cl} 0.18$ to 0.53$)$ & $0.89(95 \% \mathrm{Cl} 0.08$ to 0.94$)$ & $0.50(95 \% \mathrm{Cl} 0.28$ to 0.72$)$ & $0.80(95 \% \mathrm{Cl} 0.70$ to 0.87$)$ \\
\hline Erwin (severe sepsis) & $0.20(95 \% \mathrm{Cl} 0.05$ to 0.51$)$ & $0.94(95 \% \mathrm{Cl} 0.87$ to 0.97$)$ & $0.29(95 \% \mathrm{Cl} 0.08$ to 0.64$)$ & 0.91 (95\% Cl 0.83 to 0.95$)$ \\
\hline Shiuh & 0.75 (95\% Cl not reported) & Not reported & Not reported & Not reported \\
\hline Travers & $0.73(95 \% \mathrm{Cl} 0.61$ to 0.83$)$ & 0.79 (95\% $\mathrm{Cl} 0.75$ to 0.82$)$ & $0.31(95 \% \mathrm{Cl} 0.24$ to 0.38$)$ & $0.96(95 \% \mathrm{Cl} 0.94$ to 0.98$)$ \\
\hline
\end{tabular}

CIS, critical illness score; MEWS, Modified Early Warning Score; PRESEP, Prehospital Early Sepsis Detection. 
slightly between studies; however, once candidate predictors were identified, all studies used univariate logistic regression to determine which candidate predictors were associated with sepsis, followed by multivariable logistic regression, in a stepwise fashion, to build their respective models. Goodness of fit was assessed by HosmerLemeshow test and model performance determined by calculating the area under the receiver operating characteristic curve. ${ }^{30-32}$ Variables used in each screening tool are shown in table 3 . None of the studies included a validation study of their respective screening tools.

Seymour $e t a l^{32}$ developed the critical illness score to predict the risk critical illness among EMS patients. It was not developed to identify sepsis specifically, although the statistical estimates reported in this review relate to sepsis cases only. Their study used the clinical records of 144913 EMS patients, of whom 4895 had severe sepsis. Polito $e$ t $a l^{31}$ derived the PRESS score from a population of 66439 EMS encounters. The sample studied included 555 patients at risk of sepsis, of whom 75 were noted to have severe sepsis, while Bayer et $a l^{30}$ derived the PRESEP score from a sample of 375 EMS patients, of whom 93 had sepsis (including 60 patients with severe sepsis and 12 patients with septic shock). Accuracy of prehospital sepsis screening tools is presented in table 4 .

\section{Sepsis recognition by EMS (using a screening tool)}

We identified very low-quality evidence (downgraded for risk of bias, indirectness and imprecision), from two observational studies, ${ }^{12}{ }^{15}$ addressing recognition of sepsis by EMS personnel using a screening tool (see table 2). Guerra et $a l^{12}$ report that emergency medical technicians (EMTs) trained to recognise sepsis correctly identified $32 / 67(48 \%)$ patients with sepsis, with failure to recognise sepsis in $35 / 67(52 \%)$ of cases; however, this figure may be misleading. In 5/35 (14\%) of cases, the patient's vital signs did not meet the criteria of the sepsis screening tool while in EMS care; in 8/35 (23\%) of cases, the patients had cryptic shock but EMTs did not have lactate meters; and in 13/35 (37\%) of cases, diagnosis was made by abnormal white cell count (only available in hospital). In 9/35 (26\%) of cases, EMTs failed to identify sepsis when sufficient diagnostic criteria were available to them. The high proportion of patients missed due to lack of white cell count highlights a limitation of prehospital sepsis screening tools. Guerra et $a l^{12}$ further reported that among patients with sepsis transported by EMS crews not trained to recognise sepsis, $5 / 45(11 \%)$ were identified as patients with sepsis.

McClelland and Jones ${ }^{15}$ scrutinised the records of all patients with sepsis conveyed by a regional ambulance service to a university hospital to determine whether ambulance clinicians, previously trained in the use of a screening tool, recognised and documented suspected sepsis. The screening tool used was based on the Robson tool amended to include oxygen saturations as an indicator of organ dysfunction. The authors concluded that the use of the screening tool by ambulance clinicians was inconsistent but improved sepsis recognition.

\section{Retrospective application of EMS data to screening tool by researcher}

We identified very low-quality evidence (downgraded for risk of bias, indirectness and imprecision), from two observational studies, ${ }^{21} 30$ addressing retrospective application of prehospital data to screening tools (see table 2). Wallgren $e t a l^{21}$ compared two screening tools (Robson tool and BAS 90-30-90 score) with EMS clinician judgement. The Robson tool performed better than the BAS 90-30-90 score (see table 4). Clinician judgement, defined as 'documentation of suspected sepsis, septicaemia, urosepsis or blood poisoning in the patient's clinical record', was reported to be $11.9 \%$ and $16.9 \%$ sensitive for sepsis and severe sepsis, respectively. CIs were not reported.

Bayer $e t a l^{30}$ compared the performance of their PRESEP score with the MEWS, BAS 90-30-90 and Robson tool reporting that the PRESEP score surpassed MEWS and BAS 90-30-90 for sensitivity, specificity, positive predictive value (PPV) and negative predictive value (NPV). The Robson tool showed better sensitivity; however, the PRESEP tool had better specificity. Furthermore, the PRESEP score showed better PPV and comparable NPV than the Robson tool (see table 4).

\section{Sepsis recognition by EMS (use of screening tool not reported)}

We identified very low-quality evidence (downgraded for risk of bias, indirectness, imprecision and abstract only publication), from three observational studies, ${ }^{20} 2728$ addressing accuracy of paramedic diagnosis of sepsis in clinical practice (see table 2). All three studies were published in abstract and it is not clear if paramedics used a screening tool or if they received any training to improve sepsis recognition.

Erwin $e t a l^{20}$ compared paramedic diagnosis of sepsis and severe sepsis with physician diagnosis (see table 4). The level of agreement between paramedics and physicians was low ( $\kappa=0.25$ and 0.16 , respectively). These results lead the authors to conclude that sepsis criteria were more useful for ruling-out sepsis than diagnosing sepsis.

In the study by Shiuh et $a l,{ }^{27}$ EMS crews stratified patients with sepsis according to prehospital lactate readings. If patients had a lactate $>4 \mathrm{mmol} / \mathrm{L}$, paramedic crews provided the hospital with an 'alert' message, whereas if the lactate was in the range of $2.5-3.9 \mathrm{mmol} / \mathrm{L}$, they provided the hospital with an 'inform' message prior to, or on, hospital arrival. They reported data for 219 patients with sepsis for whom a lactate reading was available; they did not report data for those patients where a lactate reading was not known/unavailable (see table 4).

Travers $e t a l^{28}$ compared accuracy of paramedic sepsis diagnosis in 629 cases. Thermometry was not available to 
paramedics to confirm body temperature with any degree of accuracy. Paramedic diagnosis agreed with physician diagnosis in 78\% of cases. This is the largest paramedic diagnostic accuracy study, but unfortunately detail is lacking.

\section{DISCUSSION}

The studies identified provide low-quality or very lowquality evidence to suggest that accuracy of prehospital sepsis recognition by ambulance clinicians varies considerably. This variation could have numerous causes. In many areas, paramedic education programmes have not focused sufficient attention on sepsis as a clinical syndrome and paramedic knowledge of sepsis is often poor. ${ }^{5} 39-41$ It is possible that ambulance clinicians encounter patients with sepsis earlier in their clinical course, before they become seriously ill, and it is also not known if in-hospital and prehospital clinical assessments, such as blood pressure, correlate in patients with sepsis. An additional factor may be that routine in-hospital tests such as white cell count and lactate are not commonly used within EMS, which may limit the ability to extrapolate from in-hospital studies.

The majority of the prehospital sepsis screening tools rely upon the Surviving Sepsis Campaign systemic inflammatory response syndrome (SIRS) criteria which were initially described to improve sepsis recognition in the ED and intensive care environments. Although SIRS describe physiological signs marking the transition from infection to sepsis, they lack specificity for sepsis. SIRS are observable following a wide variety of insults other than infection, leading some to question the value of SIRS to identify sepsis. ${ }^{42}{ }^{43}$ Churpek et $a l^{44}$ recently demonstrated that SIRS criteria were not reliable predictors of sepsis or mortality in the ward setting. Use of SIRS criteria to identify sepsis in the prehospital environment may therefore be equally ineffective.

The three studies documenting the development of prehospital screening tools for sepsis included more organ dysfunction criteria and also included non-SIRS variables (see table 3). Among these, tools sensitivity for severe sepsis ranged from 0.76 to 0.85 , while specificity ranged from 0.47 to 0.86 ; they appear to perform better than tools based on the SIRS diagnostic criteria (see table 4); however, none have been clinically validated.

Although nine studies were identified in the course of this review, only five were concerned with screening of patients in clinical practice by EMS clinicians. ${ }^{12} 15202728$ These studies enrolled a total of 1123 patients, over half of whom (675) were in the Travers $e t a t^{28}$ study. Given the very limited number of participants in the remaining studies (range 49-183), it is unlikely that reported point estimates are sufficiently precise to draw conclusions with confidence.

\section{CONCLUSION}

The identified studies indicate that sepsis recognition within EMS is highly variable. The majority of screening tools studied in clinical practice favour SIRS criteria which may limit the specificity of these tools. Screening tools derived from EMS data have been developed; these tools appear to include more organ dysfunction variables. Retrospective application of ambulance data to these EMS-derived tools suggests that they may help improve sepsis recognition as they demonstrate similar sensitivity with greater specificity. There is a need to undertake validation studies of EMS-derived sepsis screening tools to determine their efficacy. It remains to be seen if use of a prehospital sepsis screening tool provides any significant clinical benefit.

Twitter Follow Michael Smyth at @quincy516

Contributors MAS developed the protocol, developed and ran the searches, selected and appraised papers, extracted data and drafted the initial manuscript. SJB-M selected and appraised papers, verified extracted data and revised the manuscript for important intellectual content. GDP commented on protocol, searches, evidence appraisal and revised the manuscript for important intellectual content. All authors approved the final manuscript.

Funding This work was supported by a National Institute for Health Research Clinical Doctoral Research Fellowship awarded to MAS (CDRF-2012-05-058).

Competing interests GDP is a NIHR Senior Investigator and Director of Research for the Intensive Care Foundation.

Provenance and peer review Not commissioned; externally peer reviewed.

Open Access This is an Open Access article distributed in accordance with the terms of the Creative Commons Attribution (CC BY 4.0) license, which permits others to distribute, remix, adapt and build upon this work, for commercial use, provided the original work is properly cited. See: http:// creativecommons.org/licenses/by/4.0/

\section{REFERENCES}

1. Dellinger RP, Levy MM, Rhodes A, et al. Surviving sepsis campaign: international guidelines for management of severe sepsis and septic shock: 2012. Crit Care Med 2013;41:580-637.

2. Daniels R, Nutbeam T, McNamara G, et al. The sepsis six and the severe sepsis resuscitation bundle: a prospective observational cohort study. Emerg Med J 2011;28:507-12.

3. Wang HE, Shapiro NI, Angus DC, et al. National estimates of severe sepsis in United States emergency departments. Crit Care Med 2007;35:1928-36.

4. Studnek JR, Artho MR, Garner CL Jr, et al. The impact of emergency medical services on the ED care of severe sepsis. Am $J$ Emerg Med 2012;30:51-6.

5. Wang HE, Weaver MD, Shapiro NI, et al. Opportunities for emergency medical services care of sepsis. Resuscitation 2010;81:193-7.

6. Ibrahim I, Jacobs IG. Can the characteristics of emergency department attendances predict poor hospital outcomes in patients with sepsis? Singapore Med J 2013;54:634-8.

7. Groenewoudt M, Roest AA, Leijten FMM, et al. Septic patients arriving with emergency medical services: a seriously ill population. Eur J Emerg Med 2014;21:330-5.

8. Roest AA, Stoffers J, Pijpers E, et al. Ambulance patients with nondocumented sepsis have a high mortality risk: a retrospective study. Eur J Emerg Med 2015. doi:10.1097/MEJ.0000000000000302

9. van der Wekken LC, Alam N, Holleman F, et al. Epidemiology of sepsis and its recognition by emergency medical services personnel in the Netherlands. Prehosp Emerg Care 2016;20:90-6.

10. Femling JK, Weiss SJ, Fullerton L, et al. EMS sepsis patients are different from walk-in sepsis patients. Ann Emerg Med 2012; 60:S120.

11. Gray A, Ward K, Lees F, et al. The epidemiology of adults with severe sepsis and septic shock in Scottish emergency departments. Emerg Med J 2013;30:397-401.

12. Guerra WF, Mayfield TR, Meyers MS, et al. Early detection and treatment of patients with severe sepsis by prehospital personnel. J Emerg Med 2013;44:1116-25.

13. Suffoletto B, Frisch A, Prabhu A, et al. Prediction of serious infection during prehospital emergency care. Prehosp Emerg Care 2011;15:325-30. 
14. Seymour CW, Rea TD, Kahn JM, et al. Severe sepsis in pre-hospital emergency care: analysis of incidence, care, and outcome. Am J Respir Crit Care Med 2012;186:1264-71.

15. McClelland $\mathrm{G}$, Jones J. A pilot study exploring the accuracy of pre-hospital sepsis recognition in the North East Ambulance Service. $J$ Paramedic Pract 2015;7:459-65.

16. Gu WJ, Wang F, Bakker J, et al. The effect of goal-directed therapy on mortality in patients with sepsis-earlier is better: a meta-analysis of randomized controlled trials. Crit Care 2014;18:570.

17. Moyer P, Ornato JP, Brady WJ Jr, et al. Development of systems of care for ST-elevation myocardial infarction patients: the emergency medical services and emergency department perspective. Circulation 2007;116:e43-8.

18. Abdullah AR, Smith EE, Biddinger PD, et al. Advance hospital notification by EMS in acute stroke is associated with shorter door-to-computed tomography time and increased likelihood of administration of tissue-plasminogen activator. Prehosp Emerg Care 2008;12:426-31.

19. American College of Emergency Physicians. Trauma care systems development, evaluation, and funding. Policy statement. Ann Emerg Med 2012;60:249-50.

20. Erwin A, Salzman J, Wewerka S, et al. Can paramedics accurately diagnose sepsis and severe sepsis in the field? Acad Emerg Med 2011;1:S23-4.

21. Wallgren UM, Castrén M, Svensson AE, et al. Identification of adult septic patients in the prehospital setting: a comparison of two screening tools and clinical judgment. Eur J Emerg Med 2014;21:260-5.

22. Polito $\mathrm{C}$, Isakov A, Yancey A, et al. Detection of severe sepsis in the pre-hospital setting: how are we doing? Crit Care Med 2014;1:A1603.

23. Boardman S, Richmond C, Robson W, et al. Prehospital management of a patient with severe sepsis. J Paramedic Pract 2009;1:183-8.

24. Robson W, Nutbeam T, Daniels R. Sepsis: a need for prehospital intervention? Emerg Med J 2009;26:535-8.

25. Schünemann $\mathrm{H}$, Brozek J, Guyatt $\mathrm{G}$, et al. GRADE handbook. Secondary GRADE handbook, 2013. http://www. guidelinedevelopment.org/handbook/

26. Moher D, Liberati A, Tetzlaff J, et al. Preferred reporting items for systematic reviews and meta-analyses: the PRISMA statement. $J$ Clin Epidemiol 2009;62:1006-12.

27. Shiuh T, Sweeney T, Rupp R, et al. An emergency medical services sepsis protocol with point-of-care lactate accurately identifies out-of-hospital patients with severe infection and sepsis. Ann Emerg Med 2012;1:S44

28. Travers A, Green R, Cain E, et al. Can paramedics diagnose sepsis in the prehospital setting? A feasibility study. Can J Emerg Med 2013;15:S55.
29. Seymour CW, Kahn JM, Cooke CR, et al. Out-of-hospital prediction of critical illness in a population-based cohort. Am J Respir Crit Care Med 2010;181 (Meeting Abstracts)

30. Bayer O, Schwarzkopf D, Stumme C, et al. An early warning scoring system to identify septic patients in the prehospital setting: the PRESEP score. Acad Emerg Med 2015;22:868-71.

31. Polito $\mathrm{CC}$, Isakov $\mathrm{A}$, Yancey $\mathrm{AH}$ II, et al. Prehospital recognition of severe sepsis: development and validation of a novel emergency medical services screening tool. Am J Emerg Med 2015;33:1119-25.

32. Seymour CW, Kahn JM, Cooke CR, et al. Prediction of critical illness during out-of-hospital emergency care. JAMA 2010;304:747-54.

33. Guyatt $\mathrm{GH}$, Oxman AD, Vist G, et al. GRADE guidelines: 4. Rating the quality of evidence-study limitations (risk of bias). $J$ Clin Epidemiol 2011;64:407-15.

34. Guyatt GH, Oxman AD, Kunz R, et al. GRADE guidelines: 7. Rating the quality of evidence-inconsistency. J Clin Epidemiol 2011;64:1294-302.

35. Guyatt GH, Oxman AD, Kunz R, et al. GRADE guidelines: 8. Rating the quality of evidence-indirectness. J Clin Epidemiol 2011;64:1303-10.

36. Guyatt GH, Oxman AD, Kunz R, et al. GRADE guidelines 6. Rating the quality of evidence-imprecision. J Clin Epidemio 2011;64:1283-93.

37. Guyatt GH, Oxman AD, Montori V, et al. GRADE guidelines: 5. Rating the quality of evidence-publication bias. J Clin Epidemiol 2011;64:1277-82.

38. Guyatt $\mathrm{GH}$, Oxman AD, Sultan S, et al. GRADE guidelines: 9. Rating up the quality of evidence. J Clin Epidemiol 2011;64:1311-16.

39. Seymour CW, Carlbom D, Engelberg RA, et al. Understanding of sepsis among emergency medical services: a survey study. J Emerg Med 2012;42:666-77.

40. Báez AA, Hanudel P, Perez MT, et al. Prehospital Sepsis Project (PSP): knowledge and attitudes of United States advanced out-of-hospital care providers. Prehosp Disaster Med 2013;28:104-6.

41. Shime N. A survey of the competency of ambulance service personnel in the diagnosis and management of sepsis. J Emerg Med 2015;49:147-51.

42. Kaukonen KM, Bailey M, Pilcher D, et al. Systemic inflammatory response syndrome criteria in defining severe sepsis. $N$ Engl J Med 2015;372:1629-38.

43. Vincent JL, Opal SM, Marshall JC, et al. Sepsis definitions: time for change. Lancet 2013;381:774-5.

44. Churpek MM, Zadravecz FJ, Winslow C, et al. Incidence and prognostic value of the systemic inflammatory response syndrome and organ dysfunctions in ward patients. Am J Respir Crit Care Med 2015;192:958-64. 